Vol. 10(6), pp. 254-259, 30 March, 2015

DOI: $10.5897 /$ SRE2014.5882

Article Number:6B1B1E051829

ISSN 1992-2248

Copyright@2015

Scientific Research and Essays

Author(s) retain the copyright of this article

http://www.academicjournals.org/SRE

\title{
Evaluation of potential application of micromagnetic techniques for detection of corrosion in reinforced concrete
}

\section{Carlos Henrique de Carvalho ${ }^{1 *}$, Carlos Otávio Damas Martins ${ }^{1}$, Sandro Griza ${ }^{1}$, Thomas Gabriel Rosauro Clarke ${ }^{2}$ and Ledjane Silva Barreto ${ }^{1}$}

\author{
${ }^{1}$ Federal University of Sergipe, Brazil. \\ ${ }^{2}$ Federal University of Rio Grande do Sul, Brazil.
}

Received 16 March, 2014; Accepted 5 March, 2015

\begin{abstract}
Despite the constant development of new materials, reinforced concrete is still widely used in civil engineering. Corrosion of the steel armour in reinforced concrete structures has historically been one of the main causes of damage and early failure. The development of a reliable method of non-invasive corrosion inspection and evaluation has been a challenge for many years. This paper focused on magnetic inspection of the tendons in steel armours. Results show a good correlation between micromagnetic parameters and corrosion evolution, indicating that the method is a viable option for integrity monitoring of such structures.
\end{abstract}

Key words: Reinforced concrete, corrosion monitoring, micromagnetic tests.

\section{INTRODUCTION}

Steel reinforced concrete is one of the most common materials in civil construction due to its versatility and wide acceptability by designers. Once constructed, good quality concrete can last for many years without intervention (Andrade and Dal 1999). As a disadvantage, corrosion of the steel reinforcement has been one of the predominant factors leading to premature deterioration of concrete worldwide, especially of structures located in coastal areas. This process leads to considerable maintenance costs and demands frequent structure inspection or intervention (Arndt and Jalinoos, 2009).

Literature shows that the most important causes of corrosion initiation in reinforcing steel are the ingress and contact of chloride ions and carbon dioxide on the steel surface, which causes a change in the alkaline environment provided by the concrete, thus leading to incremental degradation processes. Corrosion detection and monitoring has therefore been a significant concern for engineers and researchers in the non destructive testing area (Arndt and Jalinoos, 2009; Breysse et al., 2009; McCann and Forde, 2001; Song and Saraswathy, 2007).

Song and Saraswathy (2007) showed a good review of the application of some of the most popular corrosion monitoring techniques to reinforced concrete structure evaluation. 


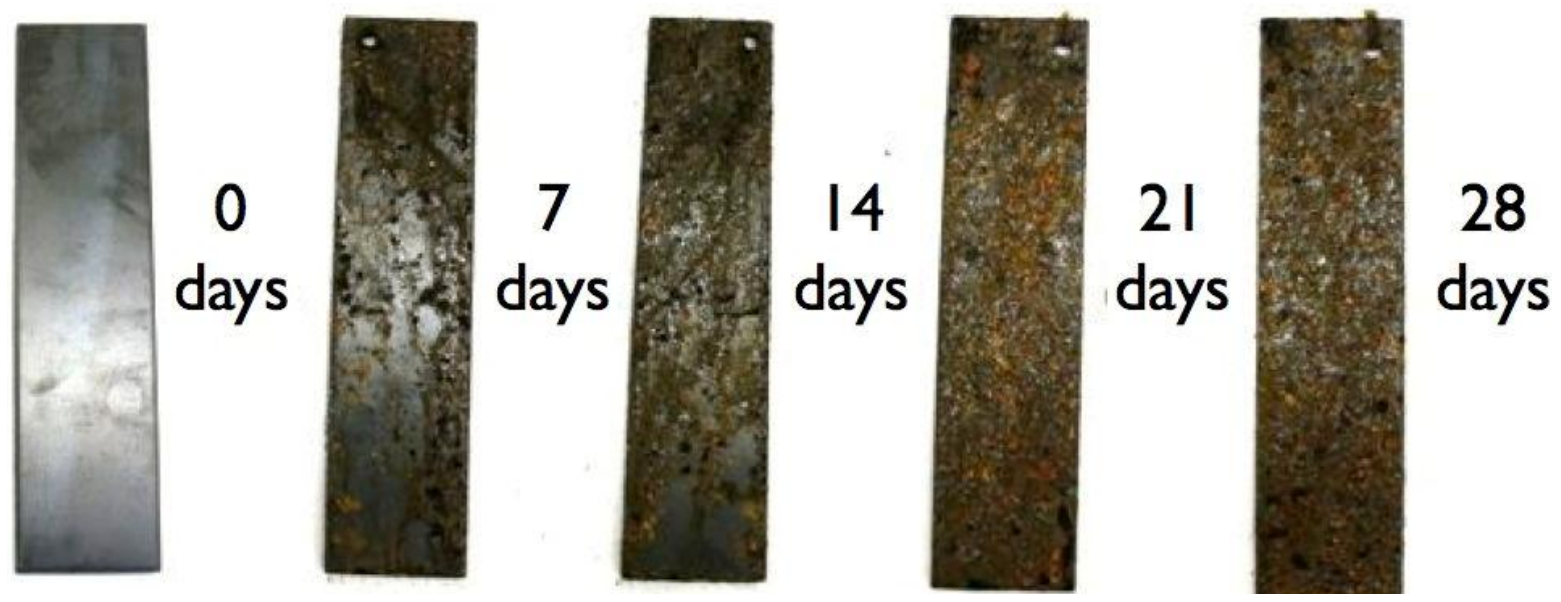

Figure 1. AISI 1020 steel samples, before and after the exposure to salt spray for the indicated period.

Arndt and Jalinoos (2009) evaluated conventional methods based on the detection of electrochemical changes in the structure. However, although cheap, these methods provide low sensitivity, and the authors acknowledge the need for further development of other non destructive techniques, such as radiography, ultrasound, thermography or electromagnetic testing.

Martins (2008), Martins and Reguly $(2009,2010)$ and Martins et al. (2013) showed results of micromagnetic methods applied to stress and toughness measurements in steels. In these techniques, microstructure-induced variations of the magnetisation characteristics of the material can be correlated to of some of its properties, traditionally those which strongly influence magnetic domain boundary motion (that is, grain boundaries, residual stresses, phase distribution) or cause changes to the induced eddy current fields.

This works aims at increasing the usual range of application of micromagnetic methods by analysing the influence of corrosion evolution on magnetic properties of AISI 1020 steels samples. Corrosion in this case is the irreversible consumption of material due to its interaction with the environment (Arndt and Jalinoos, 2009). During this process, the oxidative reactions occurring on the materials surface will alter its magnetisation characteristics, allowing this effect to be used to quantify the amount of corrosion taking place in the structure.

\section{EXPERIMENTAL PROCEDURE}

Flat samples of AISI 1020 steel $\left(5 \times 50 \times 200 \mathrm{~mm}^{3}\right)$ were used in this work. This flat geometry was selected due better configuration with the equipments magnetic probe. Also, the low carbon AISI 1020 material was chosen due to its normal application as reinforcement in concrete combining a good strength and low cost (despite its low corrosion resistance).

In order to simulate the corrosion degradation, the samples were exposed to a $5 \% \mathrm{NaCl}$ atmosphere for different periods of time $(0$, $7,14,21$, and 28 days) in a salt spray chamber (manufactured by
Bass Equipment Ltd.). The resulting aspect of the samples is shown in Figure 1.

Micromagnetic measurements were performed with a 3MA-II equipment manufactured and supplied by the IZFP Fraunhofer Institut from Germany. For magnetisation and analysis, a rectangular contact surface probe (with $50 \times 75 \mathrm{~mm}^{2}$ ) was proposed and used in this work. The basic parameters used in the measurements were: magnetic field intensity: $35 \mathrm{~A} / \mathrm{cm}$; magnetisation frequency: $200 \mathrm{~Hz}$; analysing frequency for Barkhausen noise: $0.5 \mathrm{MHz}$, and analysing frequencies for multifrequency Eddy current: $0.05,0.1,0.5$, and $1 \mathrm{MHz}$. These parameters were selected by the authors' previous experience in the field of micromagnetic analysis (Martins, 2008; Martins and Reguly, 2009, 2010; Martins et al., 2013).

As shown in Martins (2008), Martins and Reguly (2009, 2010), Martins et al. (2013), Dobmann et al. (1998), Dobmann (2007) and Yelbay (2010) the 3MA technique is based on the interaction of an external magnetic field and the ferromagnetic sample followed by the signal analysis given by four micromagnetic techniques.

Measurements were performed 40 times on each of 3 points per sample. Two concrete blocks, with 7.5 and $15 \mathrm{~mm}$-thickness each were used to vary the lift-off between the sensor and the steel sample.

This approach allowed 31 micromagnetic parameters to be obtained, which are derived from a combination of three micromagnetic techniques: harmonic analysis of the tangential field $(\mathrm{HAHt})$, Barkhausen noise (MBN), and multi frequency Eddy current analysis (MFEC). Statistical analysis and correlations of the data were performed on the MMS Software, provided with the 3MA-II equipment. Table 1 in the Annex 1 , shows the micromagnetic parameters given by the 3MA equipment (Dobmann et al., 1998). Figure 2 shows an image of the equipment and a schematic of the test configuration.

\section{RESULTS}

Results were divided in two groups depending on whether concrete lift-off layers were used or not. A statistical analysis based on multiple variable regression analysis was performed on the data obtained, and in this first analysis, in which no concrete layers were present, only parameters for one of the mentioned methods were 
Table 1. Micromagnetic parameters derived from the 3MA approach (Song and Saraswathy, 2007; Martins, 2008).

\begin{tabular}{|c|c|c|c|}
\hline & Symbol & Unit & Description \\
\hline \multirow{8}{*}{ HAHt } & $A x$ & $\mathrm{~A} / \mathrm{cm}$ & Amplitude of the harmonics of order $x$ \\
\hline & Px & [rad] & Phase angle of the harmonic of order $x$ \\
\hline & $\mathrm{Hco}$ & {$[\mathrm{A} / \mathrm{cm}]$} & Coercive field derived from technical $\mathrm{HAHt}$ \\
\hline & Hro & {$[\mathrm{A} / \mathrm{cm}]$} & Harmonic higher $\mathrm{Ht}(0)$ \\
\hline & $\mathrm{K}$ & $\%$ & Harmonic distortion \\
\hline & SAH & {$[\mathrm{A} / \mathrm{cm}]$} & Sum of the amplitudes of the harmonics $S A H=\Sigma A x$ \\
\hline & Vmag & {$[\mathrm{V}]$} & Amplitude of the output voltage to micromagnetic analysis \\
\hline & HAHt & - & Harmonic analysis of the tangential current field \\
\hline \multirow{6}{*}{ MBN } & Mmax & [V] & Maximum amplitude of the curve $\mathrm{M}(\mathrm{H})$ for a cycle of magnetization \\
\hline & Mmean & [V] & Average signal curve $\mathrm{M}(\mathrm{H})$ to a magnetization cycle \\
\hline & $\mathrm{Mr}$ & [V] & Curve measured signal $M(H)$ for $H=0 A / c m$ \\
\hline & $\mathrm{Hcm}$ & {$[\mathrm{A} / \mathrm{cm}]$} & Coercive field derived from MBM \\
\hline & $\square$ hyym & {$[\mathrm{A} / \mathrm{cm}]$} & Expansion of the curve $M(H)$ for $M=0, y y \%$ de $M m a x$ \\
\hline & MBN & - & Magnetic Barkhausen noise analysis \\
\hline \multirow{5}{*}{ MFEC } & $\operatorname{Re}^{*}$ & [V] & Real part of the eddy current signal to the frequency of $\mathrm{No}^{*}$ \\
\hline & $\mathrm{Im}^{*}$ & [V] & Imaginary part of the signal for frequency eddy current of $\mathrm{No}^{*}$ \\
\hline & Mag $^{*}$ & [V] & Magnitude of the eddy current to the frequency of $\mathrm{No}^{*}$ \\
\hline & $\mathrm{Ph}^{*}$ & [rad] & Phase angle of the eddy current signal to the frequency of $\mathrm{No}^{*}$ \\
\hline & MFEC & - & Multi-frequency eddy current analysis \\
\hline
\end{tabular}
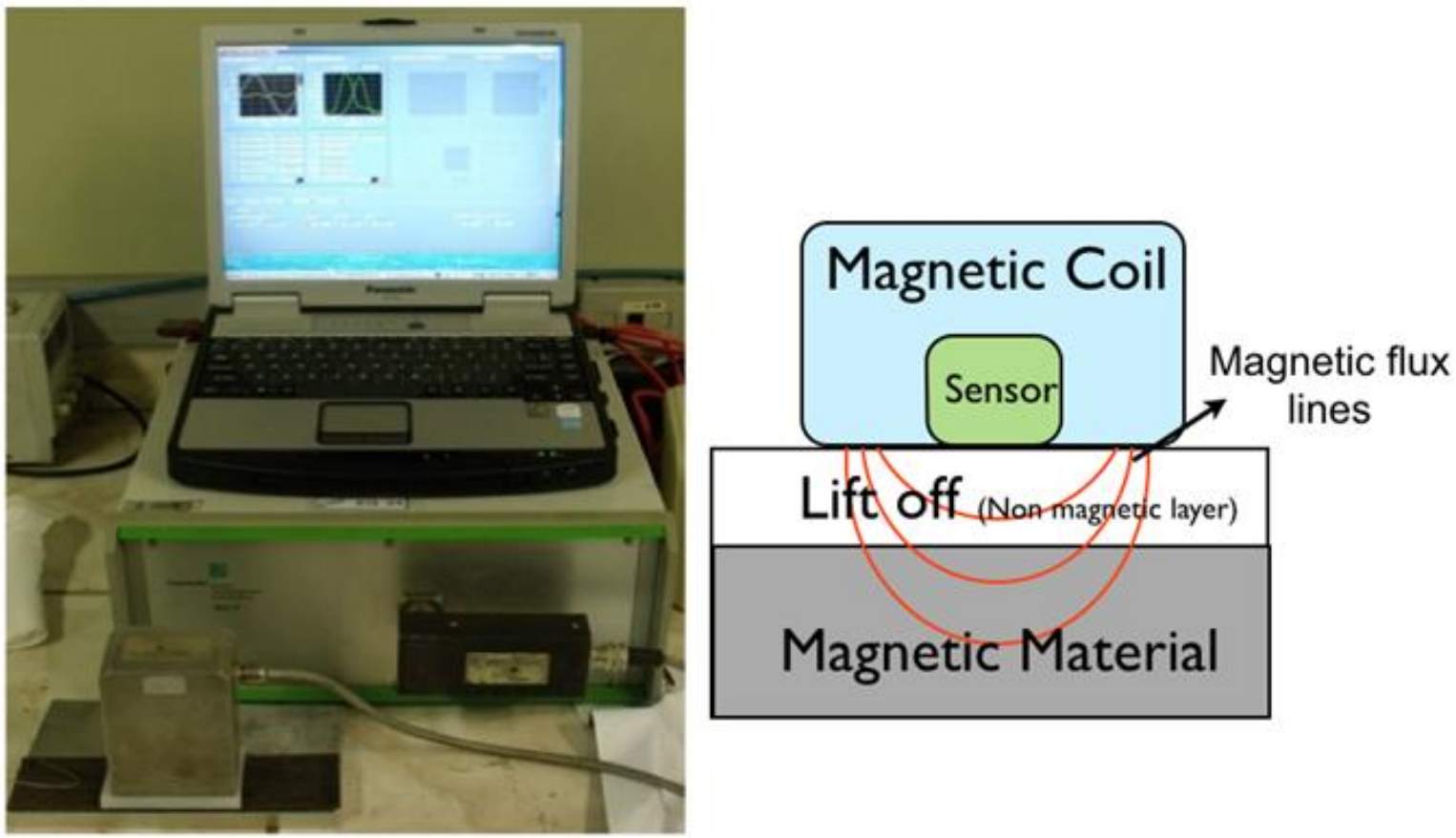

Figure 2. 3MA-II equipment and schematic of the experimental setup adopted for the measurements.

included in the analysis. Figure 3 shows the results obtained through this methodology; it shows significant data dispersion for the MBN technique $\left(R^{2}=0.836\right.$ (correlation)), which is an indicative of the low sensitivity of the MBN technique to corrosion evolution in ferromagnetic steel materials. The HAHt $\left(R^{2}=0.987\right)$ and 


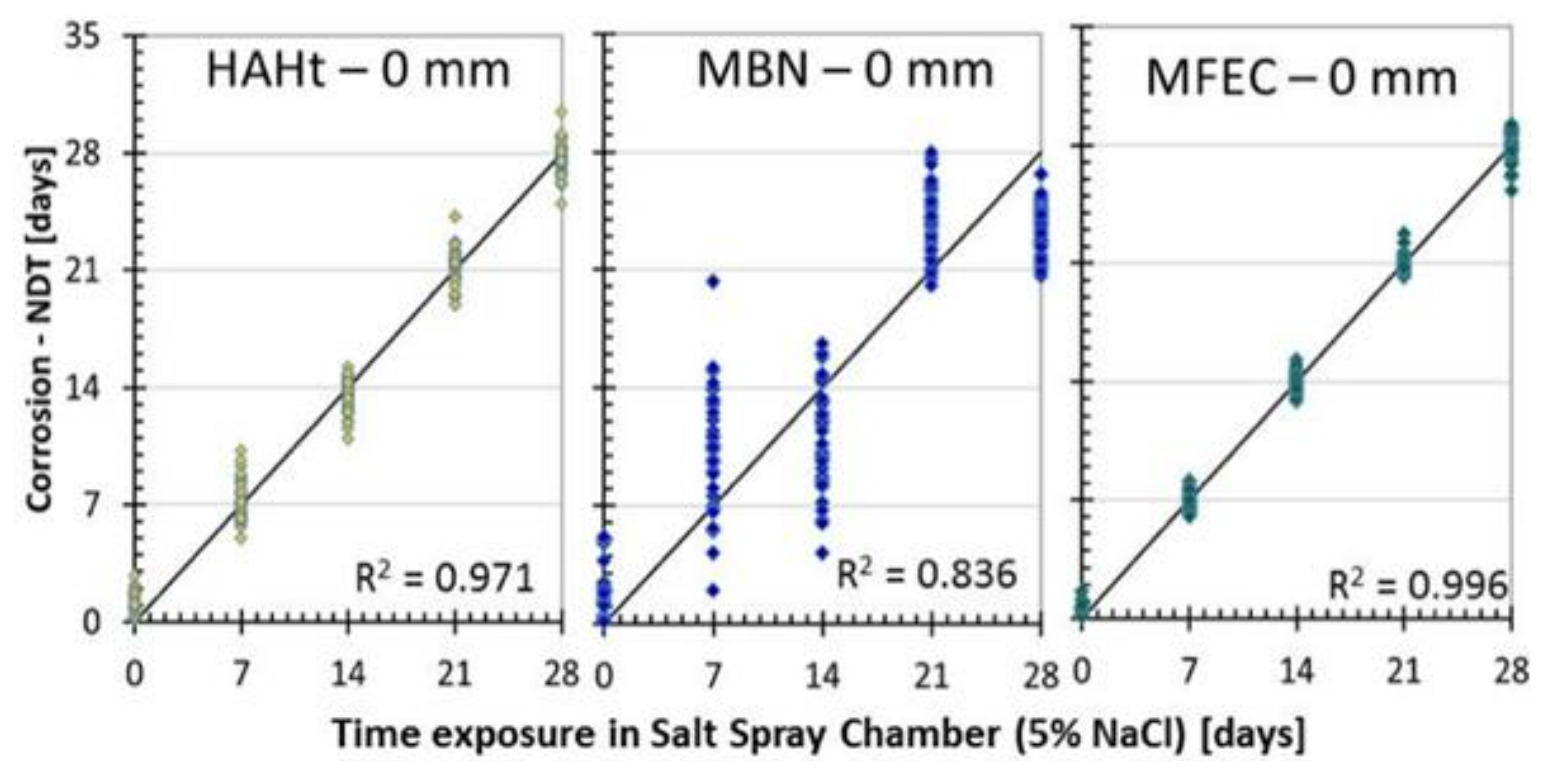

Figure 3. Micromagnetic parameters obtained from measurements on samples exposed to varying period lengths (without lift-off).

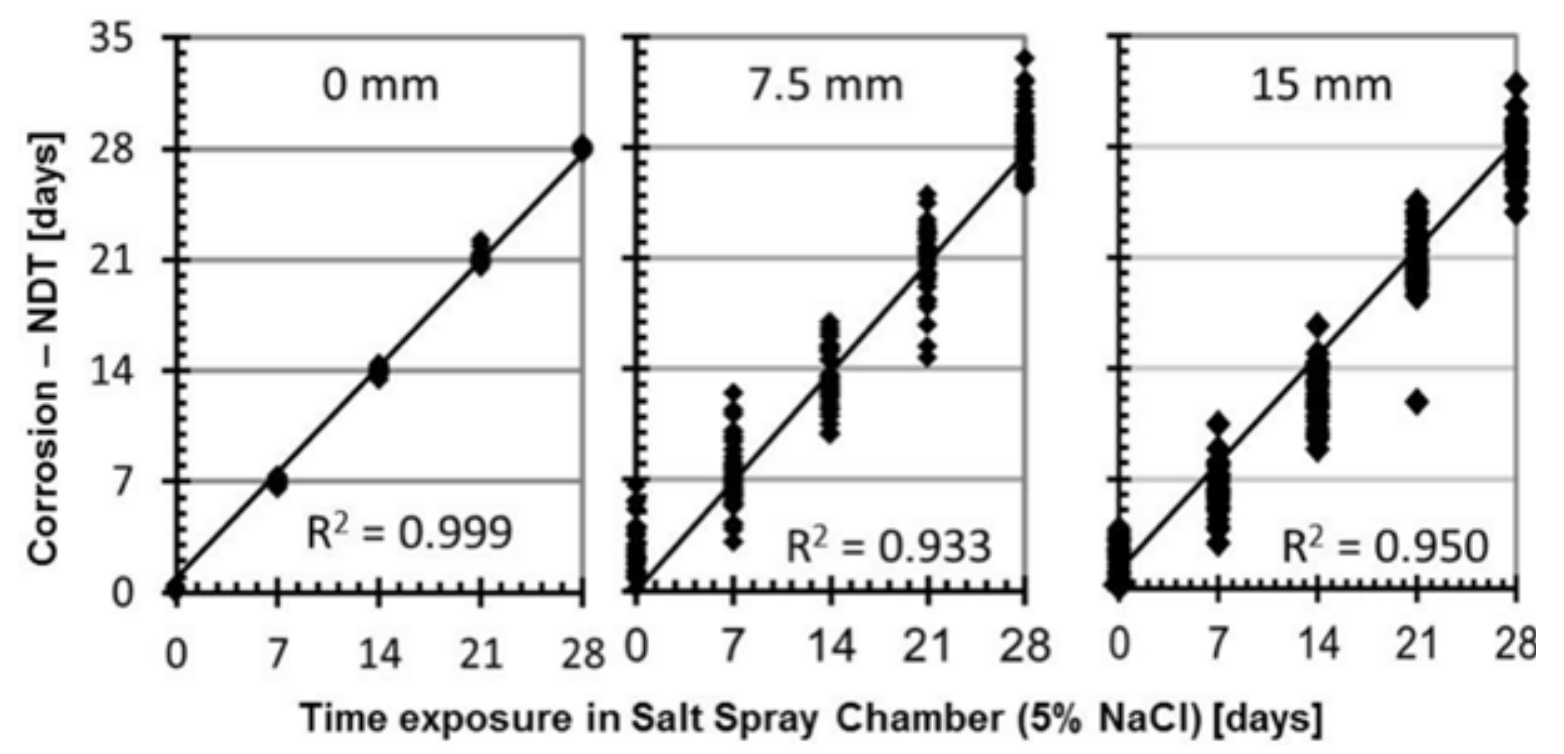

Figure 4. Micromagnetic parameters obtained from measurements on samples exposed to varying period lengths: without lift-off $(0 \mathrm{~mm})$, and with a $7.5 \mathrm{~mm}$-thick or $15 \mathrm{~mm}$-thick concrete layer used to impose different lift-offs.

MFEC $\left(\mathrm{R}^{2}=0.997\right)$ techniques provided better correlations with the corrosion evolution process, with less scatter. The equations obtained for each of the techniques after the analysis are shown in the Annex 2.

Improvements in the correlations are usually obtained if data of parameters of all methods are combined in a single regression analysis. For the measurements taken in the presence of concrete layers to simulate the lift-off seen in practical reinforced steel inspection, the lower signal-to-noise led to significantly worse result when parameters for a single method were combined.

Hence, a statistical analysis including parameters from the three techniques was performed on the data obtained when no lift-off concrete layer was present $(0 \mathrm{~mm})$, and on the data obtained when the two concrete lift-off layers (with two different thicknesses - 7.5 and $15 \mathrm{~mm}$ ) were used. Figure 4 shows that, despite the expected loss in signal intensity and the distortion in the magnetic field caused by the presence of the lift-off concrete layers, the combination of the parameters of the three micromagnetic 
techniques led to excellent correlations between the processed data and the period of exposure to salt spray.

\section{DISCUSSION}

As shown extensively in Martins (2008), Martins and Reguly (2009, 2010), Martins et al. (2013), Dobmann et al. (1998), Dobmann (2007) and Yelbay (2010), there is a basic interaction between the magnetisation characteristics and the microstructural properties of ferromagnetic materials, which allows their characterisation or inspection. During a corrosion process, the oxidation of the surface of the material will similarly influence its response to applied magnetic fields. In this sense, this work aimed at finding a good combination of magnetisation parameters, which allowed a good correlation between the measured data and the corrosion degree in these materials. If applied to reinforced concrete inspection in the civil engineering sector, the measurement procedure should also be robust when a concrete lift-off layer of different thicknesses is present. It is important to note that by the interaction of the magnetic field with the ferromagnetic material, these micromagnetic techniques can be applied for the steel bar localisation in reinforced concrete, prior to its corrosion analysis and evaluation.

Figure 3 shows the good sensitivity of the individual micromagnetic methods to the corrosion state on the samples, when no lift-off was imposed. The results were further improved when parameters of the different techniques where included in the regression analysis, as shown in Figure 4.

However, a loss of sensitivity was seen when the concrete blocks were inserted to create lift-offs of different heights. This is due to the lower intensity of the imposed magnetic field and the resulting lower signal-tonoise ratio obtained. In other words, the lift-off decreases the reliability of the micromagnetic method due to the increased path of the magnetic field from the sensor to the sample and back. Similar effects were seen in (Martins and Reguly, 2010).

The results shown in Figure 4 indicate that by combining parameters of different methods a good correlation can be obtained even when the thickest concrete block was used. If a sensor with a more adequate geometry is developed and used instead of the commercial sensor used in this work, these results are likely to improve. Nevertheless, the results indicate that a reliable procedure for micromagnetic non destructive analysis and monitoring of corrosion evolution in steel reinforcement in concrete has been demonstrated. This will be the focus of further developments of the authors.

\section{Conclusions}

Results showed good correlation between values obtained from multiple variable regression analysis of parameters given by three micromagnetic methods (harmonic analysis of the tangential magnetic field, Barkhausen noise, and multiple frequency Eddy current analysis) and the corrosion evolution obtained from exposure of steel samples to different periods of exposure to salt spray. Good correlations were found between the measured and processed data and the corrosion state of the sample even in the presence of 15 $\mathrm{mm}$-thick concrete lift-off layers.

This indicates that micromagnetic measurements are a promising way of inspecting or monitoring corrosion evolution in reinforced concrete, contributing to the development of methodologies of structural integrity evaluation and conservation for constructors and engineers.

\section{Conflict of Interest}

The authors have not declared any conflict of interests.

\section{ACKNOWLEDGEMENTS}

The authors are grateful to FAPITEC/SE and CNPq for their financial support.

\section{REFERENCES}

Andrade J, Dal Molin DA (1999). case study about degradation of reinforced concrete structures in a marine macro-environment in Brazil", International Symposium on NDT Contribution to the Infrastructure Safety Systems, RS, Brazil.

Arndt R, Jalinoos $F$ (2009). NDE for corrosion detection in reinforced concrete structures - a benchmark approach", NDTCE'09, France,

Breysse D (2009). How to improve the quality of concrete assessment by combining several NDT measurements", NDTCE'09, France,

McCann DM, Forde MC (2001). Review of NDT methods in the assessment of concrete and masonry structures", NDT\&E international, P. 34.

Song HW, Saraswathy V (2007). Corrosion Monitoring of Reinforced Concrete Structures - A Review. Int. J. Electrochem. Sci. 2:1-28.

Martins COD (2008). Desenvolvimento de metodologias de inspeção e monitoramento de risers flexíveis através de técnicas micromagnéticas de análise de tensões", PhD Thesis, PPGE3M UFRGS, P. 133.

Martins COD, Reguly A (2009). Micromagnetic stress evaluation of Flexible Riser tensile armours", Insight Vol. $51 \mathrm{~N}^{\circ} 1$, January.

Martins COD, Reguly A (2010). Lift-off influence analysis during the micromagnetic stress evaluation of flexible riser tensile armours", Insight $\mathrm{N}^{\circ} 6$, June P. 52.

Martins COD, Altenhofen A, Clarke TGR, Reguly A (2013). Applying Micromagnetic Methods for the Nondestructive Metallurgical Characterisation of an AISI 4140 Steel Materials", N ${ }^{\circ}$ 3, March Insight P. 55.

Dobmann G (2007). Industrial Applications of 3MA - Micromagnetic Multi-parameter Microstructure and Stress Analysis", $5^{\text {th }}$ ISCS2007, Romania.

Dobmann G, Altpeter I, Becker R, Kern R, Laub U, Theiner W (1998). Barkhausen noise measurements and related measurements in ferromagnetic steels", Sensing for Materials Characterisation. The ASNDT inc, P. 1. 
Yelbay HI (2010). Non-destructive determination of residual stress state in steel weldments by Magnetic Barkhausen Noise technique, ND\&T International 43:29-33.

\section{ANNEX}

\section{Equations:}

Equation 1: $R^{2}=0.987$; RMSE: 9.945 (Figure 3).

Corrosion NDT-HAHt [days] $=1316.66-587.5^{*} \mathrm{~V}_{\text {mag }}+$ $441.67^{\star} A_{3}+150.42^{\star} A_{5}-216.67^{\star} P_{3}-54.16^{*} P_{5}-92.91^{\star} \mathrm{K}$ $-38.17^{*} \mathrm{H}_{\text {ro }}$.

Equation 2: $\mathrm{R}^{2}=$ 0.836; RMSE: 8.183 (Figure 3).

Corrosion NDT-MBN [days] $=89.16^{*}-168.75^{*} \mathrm{M}_{\max }+$ $172.08^{*} \mathrm{M}_{\text {mean }}-4.5^{\star} \mathrm{H}_{\mathrm{cm}}-2.64^{*} \Delta \mathrm{H} 75 \mathrm{M}$.

Equation 3: $\mathrm{R}^{2}$ = 0.9960; RMSE: 5.045 (Figure 3).

Corrosion NDT-MFEC [days] $=22.04+1150 * \mathrm{~m}_{1}-$ $641.67^{\star} \mathrm{Mag}_{1}+5.21^{\star} \mathrm{Ph}_{1}+3658.3^{\star} \mathrm{Re}_{2}+900^{\star} \mathrm{Im}_{2}+$ $770.83^{\star} \mathrm{Mag}_{2}-9.625^{\star} \mathrm{Ph}_{2}$

Equation 4: $\mathrm{R}^{2}=$ 0.999; RMSE: 3.202 (Figure 4).

Corrosion NDT-ALL $\left[\right.$ days] $=74.33-16.25^{\star} \mathrm{P}_{3}-4.204^{*} \mathrm{UHS}$ $-4.51^{*} \mathrm{H}_{\mathrm{ro}}-1.25^{*} \mathrm{M}_{\max }+8.602^{*} \mathrm{M}_{\text {mean }}+325.87^{*} \mathrm{Im}_{3}-$ $541.56{ }^{\star} \mathrm{Mag}_{3}$.

Equation 5: $\mathrm{R}^{2}=0.9331$; RMSE: 61.432 (Figure 4).

Corrosion NDT-ALL [days] $=2201.3-2310.92 * \mathrm{~V}_{\mathrm{mag}}+$ $2224.71^{*} A_{3}+170.84^{*} A_{5}+4,92^{*} P_{5}+157,81^{*}$ UHS $948.84 * \mathrm{~K}-44.96 * \mathrm{M}_{\mathrm{r}}-8.44^{*} \mathrm{Ph}_{3}$.

Equation 6: $\mathrm{R}^{2}=0.9505$; RMSE: 51.797 (Figure 4).

Corrosion NDT-ALL [days] $=2861.82-3089.52^{*} \mathrm{~V}_{\text {mag }}+$ $1924.2^{*} \mathrm{~A}_{3}+201.25^{*} \mathrm{UHS}-853.05^{\star} \mathrm{K}+53.56^{*} \mathrm{M}_{\max }-$ $51304.5^{\star} \mathrm{Im}_{2}-12.3^{*} \mathrm{Ph}_{3}-19980.8^{*} \mathrm{Im} 4$. 